\title{
Innovation of Ideological and Political Education in Colleges and Universities from the Perspective of Network Public Opinion
}

\author{
Haixin Jiang* \\ School of Marxism, Jiamusi University, Jiamusi 154000, China \\ *Corresponding author: Haixin Jiang, 2392940446@qq.com
}

\begin{abstract}
In today's era of rapid development of network media, network public opinion has brought great changes to people's lives. As a place of frequent network public opinion, colleges and universities create a more complex and changeable network environment. This is both an opportunity and a challenge to the ideological and political education in universities. Therefore, through a brief introduction of the connotation and characteristics of network public opinion in colleges and universities, this article explores the innovation of ideological and political education in the context of network public opinion in terms of educational concepts, contents, and methods to ensure that this education plays a positive role in the new era.
\end{abstract}

Keywords: College network public opinion; Ideological and political education; Innovation

Publication date: July 2021; Online publication: July 30, 2021

\section{Connotation and characteristics of network public opinion in colleges and universities}

Network public opinion usually refers to influential opinions that are expressed by most people about real problems and phenomena existing in social life through the internet. There are many kinds of network public opinions, among which those in colleges and universities are the most important. Students are the main body of the network public opinion in colleges and universities. Through the analysis of specific events, the network public opinion in colleges and universities expresses influential or inclined suggestions.

\subsection{High quality network public opinion in universities}

Colleges and universities generally consist of students and teachers, whereby students account for a large proportion. This directly makes up two parts in the main body of the network public opinion in colleges and universities in which its quality is relatively high. Generally, teachers and students in colleges or universities would be the first to know or understand all kinds of news, events, and social hot spots in and out of the campus. With their strong ability to receive and analyze information, they would express their own unique value judgment and personal views regarding real-time problems. In addition, teachers and students would also discuss and communicate with each other on hot issues where their views and opinions would directly affect the development direction of public opinion in colleges and universities.

\subsection{Subject particularity of the network public opinion in universities}

The subjects of the network public opinion are hot social issues and new changes of social development that people focus on. The subjects of network public opinion in colleges and universities are more specific which usually refer to news or emergencies occurring on campus as well as some academic discussions. 
These would be the focus of the teachers and students in colleges and universities. The public opinions brought about by these events would have a certain effect and influence on students' thoughts and behaviors. In colleges and universities, both the teachers and students would contribute different views on the same event or issue. Then, the most agreed views would be chosen via rational judgment and analysis to form their own values as guiding roles for future behaviors.

\subsection{Diversity of online public opinion media in universities}

With the continuous development of network information, there are many kinds of media for college students to take part in network public opinion. In addition to directly expressing opinions, they can also act as important carriers of the colleges' network public opinion through Weibo, WeChat, BBS, etc. These emerging media are consistent with the age psychological characteristics of college students, reflecting their tolerance to the diversity of media in regard to public opinion behaviors. It is not difficult to browse the campus websites and find that some students and teachers would upload their works that they are interested in onto the network and share them with other people. Once these contents provoke resonance and recognition of the majority of people, a series of thinking and discussions would be brought about. The purpose for college students to surf the internet is to chat and make friends. By communicating their true feelings through social software, such communication would influence the formation of online public opinions to a certain extent. In addition, the diversity of network media would also lead to diverse online behaviors which can promote the cultural communication between different groups and generations at varying degrees.

\section{Innovation of ideological and political education in the context of network public opinion}

\subsection{Innovate ideological and political education}

\subsubsection{Establishing a sense of equality}

With the advent of the network information age, network space has already become an importance for ideological and political education. At this stage, which is the period of large information outbreaks, by means of mass communication media, college students' participation in network public opinion is increasing year by year and the subjectivity of college students is also increasing. In this way, students would receive more information related to the ideological and political education. This causes the traditional mode of ideological and political education to be unable to adapt to the development needs of the network information age. Therefore, the teaching mode of ideological and political education in colleges and universities should break the traditional teaching mode, innovate new ideas for ideological and political education, and pay attention to the cultivation of equality consciousness. Up to this point, ideological and political education teachers as the leaders of the network public opinion in colleges should use network technology to actively participate in network public opinion through discussions and also to communicate with their students as equals. Through communication, it is possible to understand the real thoughts and thinking dynamics of college students to formulate effective ideological and political education concepts in order to truly guide students in using correct network language, establish correct values and moral outlook, as well as to create a harmonious and good network public opinion environment.

\subsubsection{Establishing leading consciousness}

The information of network public opinion is updated quickly. As the subjects of network public opinion focus on campus news in colleges and universities or the hot issues of the society, college students are still at the growing stage where the development of their ideology is not yet matured causing their lack of rational thinking or extreme one-sided thinking. With the lack of proper guidance, it is easy that their 
immature comments would cause a campus public opinion crisis and this would result in a grave impact on the whole campus and even the society. In view of this situation, the ideological and political teachers in colleges and universities should take control of the situation and firmly hold the leading positions of the network public opinion in colleges and universities. The Central Committee of the Communist Party of China and the State Council have issued documents pointing out that the most critical way to occupy the position of network ideological and political education is to grasp the initiative of network ideological and political education. Ideological and political education teachers in colleges and universities should visit Weibo hot topics and WeChat public to understand the dynamics of college students, analyze the campus issues that they care about, and avoiding bad opinions which could influence the sound environment of the campus. In addition, ideological and political teachers should collect information on campus network public opinion and formulate educational goals in line with the values of the college students' network public opinion in order to better realize the goals of the education and guide students in establishing correct values.

\subsection{Innovate the contents of ideological and political education}

\subsubsection{Strengthening literacy education}

With the continuous development and change of network technology, the public opinion environment is also more complex which poses a serious threat to the traditional ethics and morality in addition to affecting the education and cultivation of cultural quality. Therefore, it is necessary to strengthen the optimization of the ideological and political education contents in colleges and universities in the context of the network public opinion as well as to adhere to the guiding ideology of the party in order to guide students to establish the correct socialist core values. In addition, there is a need to vigorously carry forward the fine traditional culture and national spirit as well as improve the humanistic and cultural quality among college students. In ideological and political education, humanistic quality education should be carried out. The essence of traditional Chinese culture should be selected to enhance the national pride, identity, and value judgement of college students to prevent the erosion of ideological construction by western values through the network of public opinions.

\subsubsection{Strengthening media literacy}

For the guidance of network public opinion in colleges and universities, there must be a clear political orientation. Colleges' network public opinion is usually a combination of the campus and the society. Since college students have active ideological consciousness and immature values, the most important task to optimize the structure of ideological and political education in colleges and universities in the context of network public opinion is to strengthen the education of media literacy among college students. The range of network public opinion is wide. Due to the lack of rich social experiences and immature knowledge structure, the network public opinion would be an imperceptible influence on college students' ideology and their mode of thinking. In view of the lack of rational judgment in college students' network information, they would be completely unable to resist the negative information on the network. Therefore, it is vital to strengthen the education on media literacy. Students' keen network recognition and critical analysis abilities help them to identify true from false network public opinion contents and make full use of network media platforms. In this complex world of network information, it is necessary to ensure that college students are able to draw valuable information data, form correct values, and cultivate a sound personality on their own in order to actively guide public opinions toward the right direction. 


\subsection{Innovate the methods of ideological and political education}

\subsubsection{Transforming the education mode from one-way indoctrination to equal inspiration}

The traditional mode of ideological and political education is dominated by teachers rather than students where teachers organize and play the leading roles in the education process. This way of education is mainly a one-way indoctrination.

However, with openness and interaction, network media has affected students' thoughts and behaviors to a large extent, thus changing the cognitive mode in college students. Therefore, the traditional mode of ideological and political education has been unable to meet the needs of the social network development. In view of that, students should be the main body in the network public opinion environment of ideological and political education while teachers should inspire and guide them in strengthening their education. Moreover, ideological and political education should start from the daily lives of college students by understanding their learning, living conditions, and interpersonal relationships in order to correctly guide their thoughts and emotions in preventing them from venting their negative emotions through network public opinion which would cause a series of unpleasant effects.

\subsubsection{Transforming the educational means from single to multiple}

The ideological and political education in colleges and universities is deeply influenced by traditional ideas and the means of education are relatively single. Hence, the teaching effect is not obvious, and it is difficult to adapt to the social development. The development of network technology greatly enriched the methods of ideological and political education in colleges and universities. Ideological and political teachers should make full use of QQ, WeChat social software, form class groups, and then penetrate the difficult contents of ideological and political education via group communication in class, grades, and also through the construction of a public campus with regular updates, sharing, learning related problems, as well as actively use public opinions as guidance. By exerting the interactive function and using the information activity place of class groups to overcome the limitations of traditional classroom teaching and space, it is possible to transfer information, exchange ideas, and guide public opinions with the help of network technology, so as to imperceptibly realize the ideological and political education in college students.

\section{Conclusion}

In a word, for ideological and political education in colleges and universities, the emergence of college network public opinion is both an opportunity and a challenge. This emergence has opened up new environments and situations where ideological and political education breaks the ideas and modes of traditional education, innovates ideological and political education methods, actively explores the positive energy of network information by making use of the network technology, and effectively guides the network public opinion to ensure that the education plays a role in its own advantages in improving the ideological and political construction among college students to establish correct values.

\section{Disclosure statement}

The author declares that there is no conflict of interest.

\section{References}

[1] Jing J, Han K, 2015, Construction of Network Public Opinion Ecology in Colleges and Universities Based on the Perspective of Effectiveness Realization of Ideological and Political Education. Research on Higher Education in Heilongjiang Province, (02). 
[2] Yang J, 2014, Ideological and Political Education of College Students from the Perspective of Optimizing Acceptance. Journal of Guizhou Radio and TV University, (01).

[3] Han J, 2015, Influence of Socialist Core Values on Ideological and Political Education of College Students. Journal of West Yunnan Normal University of Science and Technology, (03).

[4] Wang J, 2016, Comparison and Enlightenment of Ideological and Political Education in Chinese and German Universities. Modern Communication, (21).

[5] He R, 2015, Research on Countermeasures of Ideological and Political Education in Colleges and Universities to College Students' "Indoor" Phenomenon. China Education Journal, (S1).

[6] Yin D, 2015, Analysis on the Causes and Countermeasures of the Weakening of the Effectiveness of Ideological and Political Education in Universities. China Education Journal, (S2).

[7] Wang Y, Liu M, 2015, Challenges and Countermeasures of Ideological and Political Education in Colleges and Universities Under the Background of Network Times. China Education Journal, (S2).

[8] Liu C, Sun Y, 2005, On the Situation and Measures of College Students' Ideological and Political Education Under the Condition of Market Economy. Journal of Inner Mongolia University for Nationalities, (02).

[9] Wei L, Gao S, Wen X, et al., 2016, Research on the Operation and Development Strategy of Wechat Ideological and Political Education Platform of "Skinfire Youth Club". Chinese Journal of Medical Education, (04).

[10] Hu B, Kong L, Dong L, 2017, Research on the Integration of Hospital History and Culture into the Ideological and Political Education of Medical Students. Chinese Journal of Medical Education, (03). 